\title{
Increased levels of DNA methyltransferases are associated with the tumorigenic capacity of prostate cancer cells
}

\author{
GIOVANNI LUCA GRAVINA ${ }^{1,2}$, GUIDO RANIERI ${ }^{3}$, PAOLA MUZI $^{4}$, FRANCESCO MARAMPON $^{1,2}$, \\ ANDREA MANCINI $^{5}$, BORIS DI PASQUALE ${ }^{3}$, LUIGI DI CLEMENTE $^{3}$, VINCENZA DOLO $^{6}$, \\ ANNA MARIA D'ALESSANDRO ${ }^{6}$ and CLAUDIO FESTUCCIA ${ }^{1}$
}

\author{
${ }^{1}$ Department of Biotechnological and Applied Clinical Science, Laboratory of Radiobiology, and ${ }^{2}$ Department of \\ Biotechnological and Applied Clinical Science, Division of Radiation Oncology, University of L'Aquila; ${ }^{3}$ Division of Urology, \\ San Salvatore Hospital; ${ }^{4}$ Department of Biotechnological and Applied Clinical Science, General Pathology Laboratory, \\ ${ }^{5}$ Department of Biotechnological and Applied Clinical Science, Biochemistry Laboratory, and ${ }^{6}$ Department of \\ Health, Life and Enviromental Sciences, Clinical Pathology Laboratory, University of L'Aquila, L'Aquila, Italy
}

Received August 3, 2012; Accepted September 7, 2012

DOI: 10.3892/or.2012.2192

\begin{abstract}
DNA methylation might be the earliest somatic genome changes in prostate cancer that also play an important role in the process of tumor invasion, growth and metastasis. In recent years, several inhibitors of DNA methyltransferases (DNMTis) have been developed and evaluated in pre-clinical models and in clinical trials. While these compounds are effective in the treatment of hematological conditions, clinical trials in solid tumors and in prostate cancer have shown limited or no efficacy. This may be attributed to inappropriate dose regimens leading to toxicity-related adverse events. As with other anti-target compounds, one of the obstacles encountered with DNMTis in prostate cancer could be the inability to select patients for the clinical studies as well as the inability to monitor the efficacy of the drug if not the conclusion of the study. Primary cultures derived from human prostatic tissues harvested from patients with benign prostatic hyperplasia (BPH) and prostate cancer (PCa) as well as neoplastic and non-neoplastic prostate cell lines were tested for DNMT expression/activity and to monitor azacitidine molecular efficacy. We observed that in primary cultures the levels of DNMT activity as well as the protein levels of DNMT1, DNMT3a and DNMT3b were higher in cultures derived from PCa compared to BPH tissue samples and significantly higher in cultures derived from PCa with Gleason scores $\geq 7$ compared to those observed in cultures derived from Gleason scores $<7$. In addition, DNMT activity as well as DNMT1, DNMT3a and
\end{abstract}

Correspondence to: Dr Claudio Festuccia, Department of Biotechnological and Applied Clinical Science, Laboratory of Radiobiology, University of L'Aquila, Medical School, Via Vetoio, Coppito 2, I-67100 L'Aquila, Italy

E-mail: claudio.festuccia@univaq.it

Key words: prostate cancer, epigenome, DNA methyltransferase
DNMT3b levels were higher in PCa cell lines compared to their non-neoplastic counterparts. Although DNMT activity was higher in high tumorigenic/aggressive PCa cell lines compared to low tumorigenic/aggressive cell lines, only the levels of DNMT3a and DNMT3b were significantly higher in the first group of cells, suggesting that DNMT1 activity is related to the transition to non-neoplastic versus neoplastic phenotype whereas the de novo methylation enzymes were mainly related to progression. Nevertheless, the comparison in the more aggressive PC3 cell derivatives (PC3-LN4 cells) also possessed higher levels of DNMT1 compared to PC3 and PC3M from which these cells were derived. Collectively, our results confirm previous data on the increased methylation in more aggressive tumors supporting the use of DNMTis in advanced prostate cancer. In addition, since glutathione S-transferase- $\pi$ (GSTP1) was re-expressed or its protein levels were increased after treatment with non-toxic azacitidine doses and since GSTP1 can easily be measured in patient sera, the monitoring of this protein may aide in the evaluation of therapy in future clinical trials.

\section{Introduction}

Prostate cancer $(\mathrm{PCa})$ is one of the most commonly diagnosed male cancers in Western countries and is a leading cause of cancer mortality (1). Radical prostatectomy and/or local radiotherapy are the standard treatment for patients with organ-confined PCa. However, in $15-30 \%$ of these patients, PCa progresses as metastatic disease (2).

Epigenetic inactivation of genes in cancer cells is largely based on transcriptional silencing by aberrant $\mathrm{CpG}$ methylation of $\mathrm{CpG}$-rich promoter regions. Disruption in the DNA methylation machinery resulting in global hypomethylation and regional hypermethylation is well documented in most types of cancer affecting gene activity. Genes with unmethylated $\mathrm{CpG}$ islands are competent for regulated transcription, responding to signaling cues by recruiting trans-activating factors that modify nucleosome and chromatin structure, 
using histone acetyltransferases and histone methyltransferases to promote transcript synthesis by RNA polymerases. By contrast, genes with methylated $\mathrm{CpG}$ islands tend to be incompetent for expression, tightly wound around nucleosomes in a repressive chromatin structure maintained by histone deacetylases (HDACs) and other enzymes. Thus, somatic increases in $\mathrm{CpG}$ island methylation in cancer cells have been associated with gene silencing and heterochromatinization. Bedford and van Helden in 1987 (3) observed that DNA methylation levels were significantly lower in prostates with benign prostatic hyperplasia (BPH) and metastatic tumors. By contrast, non-metastatic prostate tumor DNA had a 5-methylcytosine content essentially the same as in normal tissue.

Prostatic carcinogenesis has been associated with the loss of glutathione S-transferase- $\pi$ (GSTP1) by methylation evident in some $5-10 \%$ of proliferative inflammatory atrophy (PIA) lesions, the earliest prostate cancer precursors, and in $<70 \%$ of prostatic intraepithelial neoplasia lesions $(4,5)$. Human prostate cancer cells devoid of GSTP1 better activate heterocyclic amine carcinogens, such as those found in overcooked meats, to mutagenic species than cells capable of GSTP1 expression (6). GSTP1 silencing early during the pathogenesis of prostate cancer, with the resultant loss of enzymatic protection against reactive chemical species, may offer an explanation for the well-known sensitivity of human prostatic carcinogenesis to dietary and lifestyle habits (7-9).

Three major enzymes are responsible for DNA methylation in eukaryotes: DNMT1, DNMT3a and DNMT3b (10-12). DNMT1 has been implicated primarily in the maintenance of methylation patterns that occurs during cellular replication and it preferentially methylates hemi-methylated DNA. It has been the most extensively studied maintenance methyltransferase and is abundant in tumor cells and tissues. DNMT3a and DNMT3b are known to be de novo methylators of CpG sites, which have higher methyltransferase activity for unmethylated DNA than DNMT1 and can contribute to de novo methylation during embryogenesis and tumorigenesis. In the transgenic mouse model of PCa (TRAMP), DNMT expression increases during the progressive stages of PCa $(13,14)$. The DNMT inhibitor 5-azacytidine (5-aza-CR) as well as its deoxyderivative, 5-aza-2'-deoxycytidine (5-aza-CdR), prevents prostatic disease progression and the development of lymph node metastases in this model (15). Demethylating agents have been shown to be effective in the treatment of myelodysplastic syndromes (16). While in vitro experiments and animal models have shown that 5-aza-CR has antitumor activities in several types of cancer, including prostate cancer (17-21), clinical trials with 5-aza-CR (Vidaza) or its deoxy derivative 5-azaCdR (decitabine) for the treatment of solid tumors have shown no significant effects due to the high side-effects $(22,23)$. The majority of genes activated by demethylating agents, such as $\mathrm{Rb}, \mathrm{p} 16, \mathrm{E}$-cadherin, APC, VHL, retinoic acid receptor $\beta$, BRCA1 and DLC-1, are, however, tumor-suppressor genes and are related to chemo-resistance $(21,24)$ in different types of cancer cells. We previously reported that prostate tumor cells may acquire androgen independence upon hormone therapy through epigenetic mechanisms involving modifications of DNMT expression and activity both in patients treated with bicalutamide as neoadjuvant hormone therapy (NHT) and in vitro systems (25-27). In addition, it has been shown that upon castration, the TRAMP mouse develops "castrationresistant' prostate tumors similar to those seen with the recurrence of human prostate tumor growth after androgendeprivation therapy. Treatment with 5-aza-CdR was found to increase survival of TRAMP mice and delayed prostate cancer progression, including the recurrence of prostate tumor growth after castration $(12,13)$. We also demonstrated that azacitidine was able to amplify or restore bicalutamide treatment $(26,27)$ or chemotherapy (21). In the present study, we analyzed the expression of DNMT1, DNMT3a and DNMT3b in primary culture from BPH and PCa human tissue samples as well as in neoplastic and non-neoplastic prostate epithelial cells.

\section{Materials and methods}

Reagents. All the materials for tissue culture were purchased from Hyclone (Cramlington, NE, USA). Plasticware was obtained from Nunc (Roskilde, Denmark). Azacitidine $\left(\right.$ Vidaza $\left.^{\circledR}\right)$ was obtained in collaboration with Celgene Corp. (Summit, NJ, USA). Antibodies against cytokeratin 8 (K8), 5 (K5) and 14 (K14) and PSA, vimentin (VMNT) and AMACR were purchased from Santa Cruz Biotechnology (Santa Cruz, CA, USA). Anti-DNMT1, DNMT3a and DNMT3b antibodies were purchased from BioCarta (Hamburg, Germany). GSPT1 monoclonal antibody (ALX-804-510) was purchased from Enzo Life Sciences (Vinci-Biochem Srl Florence, Italy).

Cell lines. We used non-tumor prostate epithelial cell lines [BPH-1, RWPE-1 and EPN (28)] and 9 PCa cells lines [CWR22 (29), 22Rv1 (29), LAPC-4 (30), LNCaP, VCaP (31), DuCaP (31), C4-2B (32), DU145 and PC3]. PC3 and LNCaP cell derivatives (PCM, PC3-Pro4, PC3-LN4, LNCaP-Pro5 and LNCaP-Ln5) were kindly provided by Dr I.J. Fidler and Dr C.A. Pettaway (33). Cells were cultured as previously described.

Primary tumor cultures. The primary tumor cultures of PCa were established from specimens of consenting patients undergoing radical prostatectomy. A wedge-shaped specimen of the fresh prostate was removed within $1 \mathrm{~h}$ of surgery. Frozen sections of a part of this tissue were used to confirm the prostatic origin and for diagnosis. We analysed 10 tissues harvested from $\mathrm{BPH}$ and 40 tissues derived from patients with clinically localized tumors surgically treated with prostatectomy as previously described (34-36). Tissue samples were minced and cultured in DMEM.

Preparation of cell lysates and western blot analysis. Cells were washed with cold PBS and immediately lysed with $1 \mathrm{ml}$ lysis buffer (50 mM HEPES, pH 7.5, $150 \mathrm{mM} \mathrm{NaCl}, 10 \%$ glycerol, $1 \%$ Triton X-100, 1 mM EDTA, 1 mM EGTA, 50 mM $\mathrm{NaF}, 1 \mathrm{mM}$ sodium orthovanadate, $30 \mathrm{mM}$ p-nitrophenyl phosphate, $10 \mathrm{mM}$ sodium pyrophosphate, $1 \mathrm{mM}$ phenylmethylsulfonyl fluoride, $10 \mu \mathrm{g} / \mathrm{ml}$ aprotinin and $10 \mu \mathrm{g} / \mathrm{ml}$ leupeptin). The nuclear extracts were collected as described: cells were scraped in $1 \mathrm{ml}$ PBS-EDTA and centrifuged at 3,000 rpm. Pellets were resuspended in $1 \mathrm{ml}$ harvest buffer containing $10 \mathrm{mM}$ HEPES, pH 7.9, $50 \mathrm{mM} \mathrm{NaCl}, 0.5 \mathrm{M}$ sucrose, $0.1 \mathrm{mM}$ EDTA and $0.5 \%$ Triton X-100 and incubated on ice for $5 \mathrm{~min}$. Cells were pelleted at $1,000 \mathrm{rpm}$ with a table top swinging microfuge, washed and resuspended in $1 \mathrm{ml}$ of $10 \mathrm{mM}$ HEPES, 

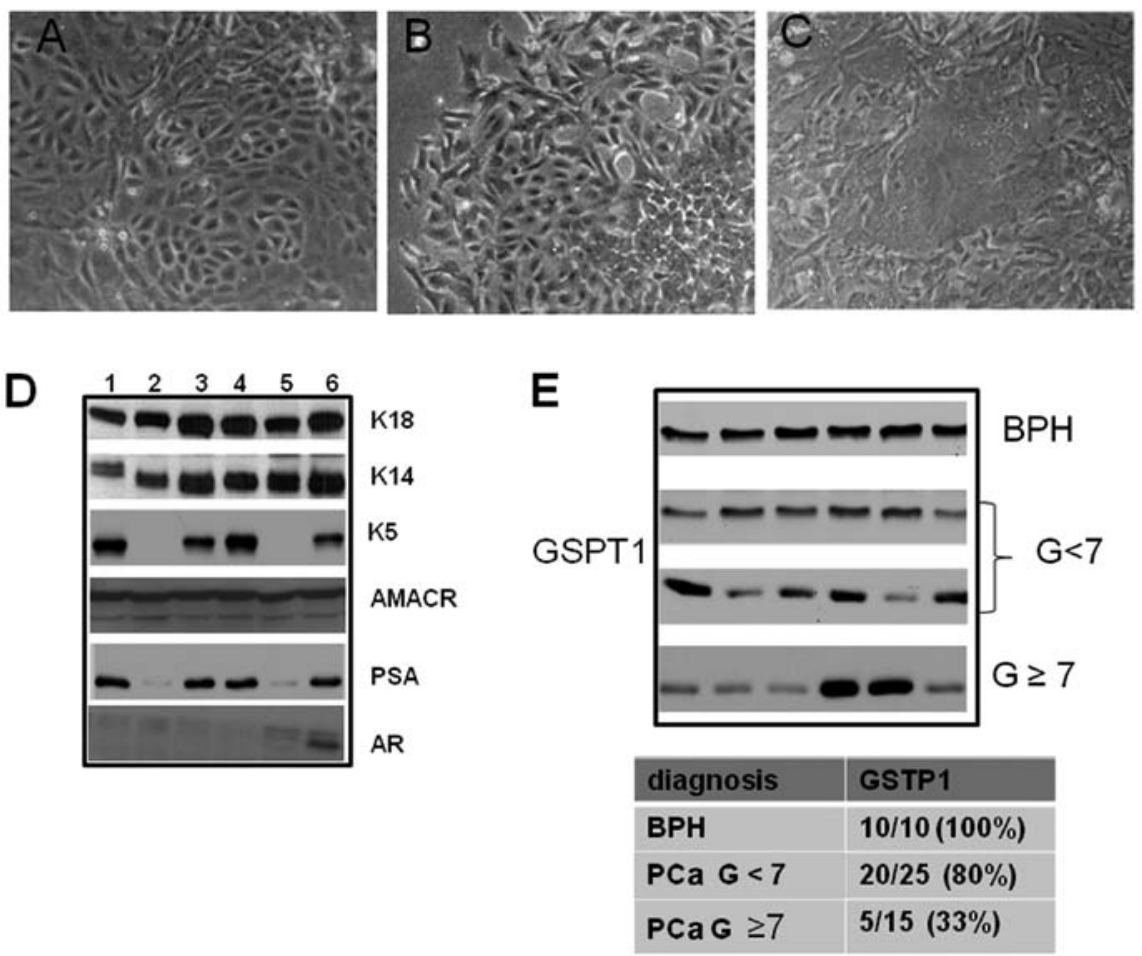

Figure 1. (A-C) Three examples of prostate epithelial cultures with small polygonal cells with dark granules. (A) Large polyclonal cells, (B) irregular colonies, (C) shows senescent signs such as multinuclear aspect and flattened epithelial sheets with a final tendency to intersect. (D) Cells were positive for K18 and K14. Low expression of AR and PSA was present. Only AMACR positive cultures were used in our study. (E) GSTP1 demonstrated by western blot analysis and densitometric evaluation. G, Gleason score.

pH 7.9 containing $10 \mathrm{mM} \mathrm{KCl}, 0.1 \mathrm{mM}$ EDTA and $0.1 \mathrm{mM}$ EGTA. Lysates were electrophoresed in 7\% SDS-PAGE and separated proteins were transferred to nitrocellulose and probed with the appropriate antibodies using the conditions recommended by the suppliers.

DNA methyltransferase activity assay. DNMT activity was evaluated by a colorimetric EpiQuik DNMT Activity Assay kit (BioVision, Mountain View, CA, USA) in nuclear extracts of cells treated with 5-Aza-CR according to the manufacturer's instructions.

Statistical analysis. Continuous variables were summarized as mean and standard deviation (SD) or as median and 95\% CI for the median. For continuous variables not normally distributed, statistical comparisons between control and treated groups were established using the Kruskal-Wallis tests. For continuous variables normally distributed, statistical comparisons between control and treated groups were established by the ANOVA test or by the Student's t-test for unpaired data (for two comparisons).

\section{Results}

Characterization of primary epithelial cancer cell cultures was performed as previously described (43-45). Organoids and small cell aggregates similar to acini attached within 2-5 days of primary culture and small outgrowths appeared with cells forming polygonal colonies of various grades of architecture. A morphological aspect of three prostate epithelial cultures with small polygonal cells containing dark granules and large polyclonal cells are shown in Fig. 1. Some cells formed small compact isles and acquired a wavy pattern. Moreover, we observed that some cells formed irregular colonies showing senescent signs such as multinuclear aspect and flattened epithelial sheets with a final tendency to intersect. Cells were positive for K18, which are typical of prostatic lumenal cells, and for K14, typical of basal cells with variable levels of K5, typical for intermediated/amplifying cells. Low expression of AR and PSA characterized our primary cell cultures whereas AMACR was present in $\sim 70 \%$ of primary cultures. Only AMACR positive cultures were used in our study. In Fig. 1D we show the expression of the above-mentioned markers in AMACR positive cultures. A densitometric analysis of the GSTP1 expression (Fig. 1E) allowed us to observe that 10/10 (100\%) of BPH cultures were GSTP1 positive whereas $62.5 \%$ (25/40) of PCa cultures showed GSTP1 protein. Following randomization in two groups based on the Gleason score, 5/25 (20\%) cultures containing low/absent levels of GSTP1 were grouped in the Gleason score $<7$ whereas 10/15 (66.7\%) with low/absent levels of GSTP1 were in the Gleason score $\geq 7$ group. In addition, we showed that 5-aza-CR was able to re-express GSTP1 in human primary cell cultures (Fig. 2), suggesting that GSTP1 may be considered a potentially useful biomarker for the methylation status of prostate cancer cells, which is in accordance with previous reports (11-14).

DNMT activity and expression in primary cultures derived from $\mathrm{BPH}$ and PCa tissue samples. We also demonstrated that 


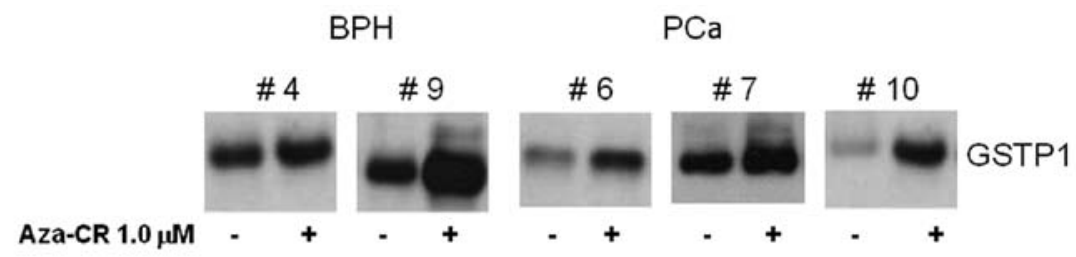

Figure 2. GSTP1 was increased in positive cultures (BPH \#4 and \#9 or PCa \#6 and \#7) and restored in very low/absent (PCa \#10) cultures. The levels of increment is proportional to the amount of DNT activity of single cultures.
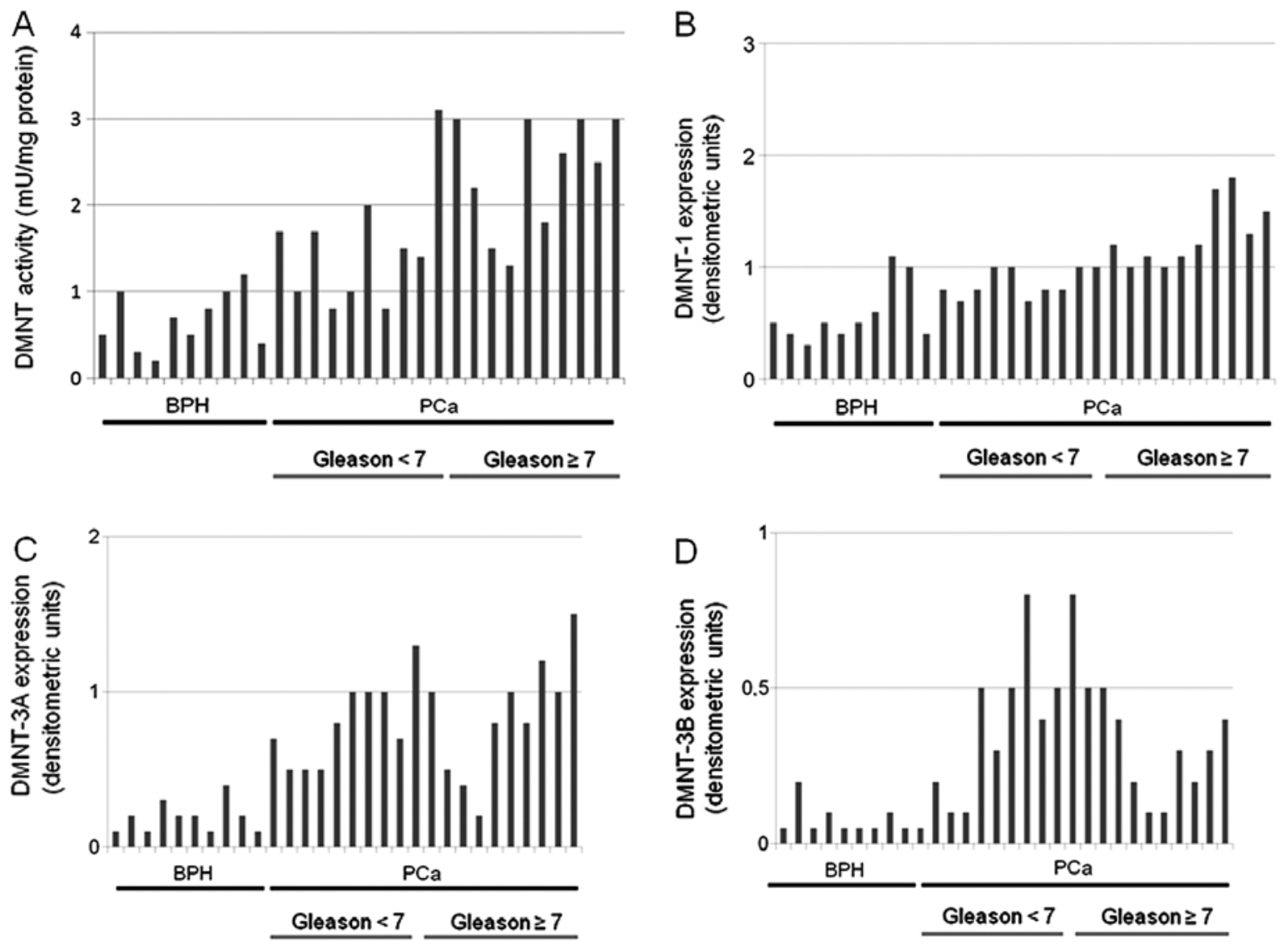

Figure 3. DNMT activity and expression in primary cultures derived from BPH and PCa tissue samples. Single values of DNMT activity in representative BPH (10/10), PCa Gleason $<7$ (10/25) and PCa Gleason $\geq 7$ (10/15) are shown. (A) DNMT activity was higher in primary cultures derived from PCa compared to BPH tissue samples. DNMT activity was also significantly higher in cultures derived from Gleason score $\geq 7$ compared to those observed in Gleason score <7-derived cultures. (B) DNMT1 expression levels were higher in PCa-derived cultures compared to BPH cultures and significantly higher in cultures derived from Gleason score $\geq 7$ compared to those observed in Gleason score $<7$-derived cultures. (C) DNMT3a expression levels were higher in PCa-derived compared to BPH-derived cultures and similar in cultures derived from Gleason score $\geq 7$ compared to those observed in Gleason score $<7$-derived cultures. (D) DNMT3b protein levels were higher in PCa-derived compared to BPH-derived cultures and statistically lower in cultures derived from Gleason score $\geq 7$ compared to those observed in Gleason score < 7 -derived cultures.

DNMT activity was higher in primary cultures derived from PCa compared to BPH tissue samples. In Fig. 3A we show single values of DNMT activity in representative BPH $(10 / 10)$, PCa Gleason $<7(10 / 25)$ and PCa Gleason $\geq 7(10 / 15)$. The differences between the values of DNMT activity observed in BPH-derived cultures $(0.68 \pm 0.30 \mathrm{mU} / \mathrm{mg}$ of protein $)$ were significantly lower compared with those observed in PCa-derived cultures $(1.90 \pm 0.81 \mathrm{mU} / \mathrm{mg}$ of protein, $\mathrm{P}<0.001)$. DNMT activity was significantly higher in cultures derived from Gleason score $\geq 7(2.31 \pm 0.70 \mathrm{mU} / \mathrm{mg}$ of protein) compared to those observed in Gleason score $<7$ derived cultures $(1.49 \pm 0.72 \mathrm{mU} / \mathrm{mg}$ of protein, $\mathrm{P}<0.005)$. The evaluation of the levels of DNMT1 also shows that PCa-derived cultures resulted in higher levels of protein compared to BPH cultures. In Fig. 3B we showed single values of DNMT1 protein expression in representative BPH (10/10), PCa Gleason $<7(10 / 25)$ and PCa Gleason $\geq 7(10 / 15)$. The differences between the values of arbitrary densitometric units for DNMT1 protein observed in BPH-derived cultures $(0.56 \pm 0.27 \mathrm{ADU})$ were significantly lower compared with those observed in PCa-derived cultures (1.09 \pm 0.33 ADU, $P<0.001)$. The DNMT1 protein levels were significantly higher in cultures derived from Gleason score $\geq 7$ (1.31 $\pm 0.32 \mathrm{ADU})$ compared to those observed in Gleason score $<7$ derived cultures $(0.86 \pm 0.13 \mathrm{ADU}, \mathrm{P}<0.001)$. Evaluation of 

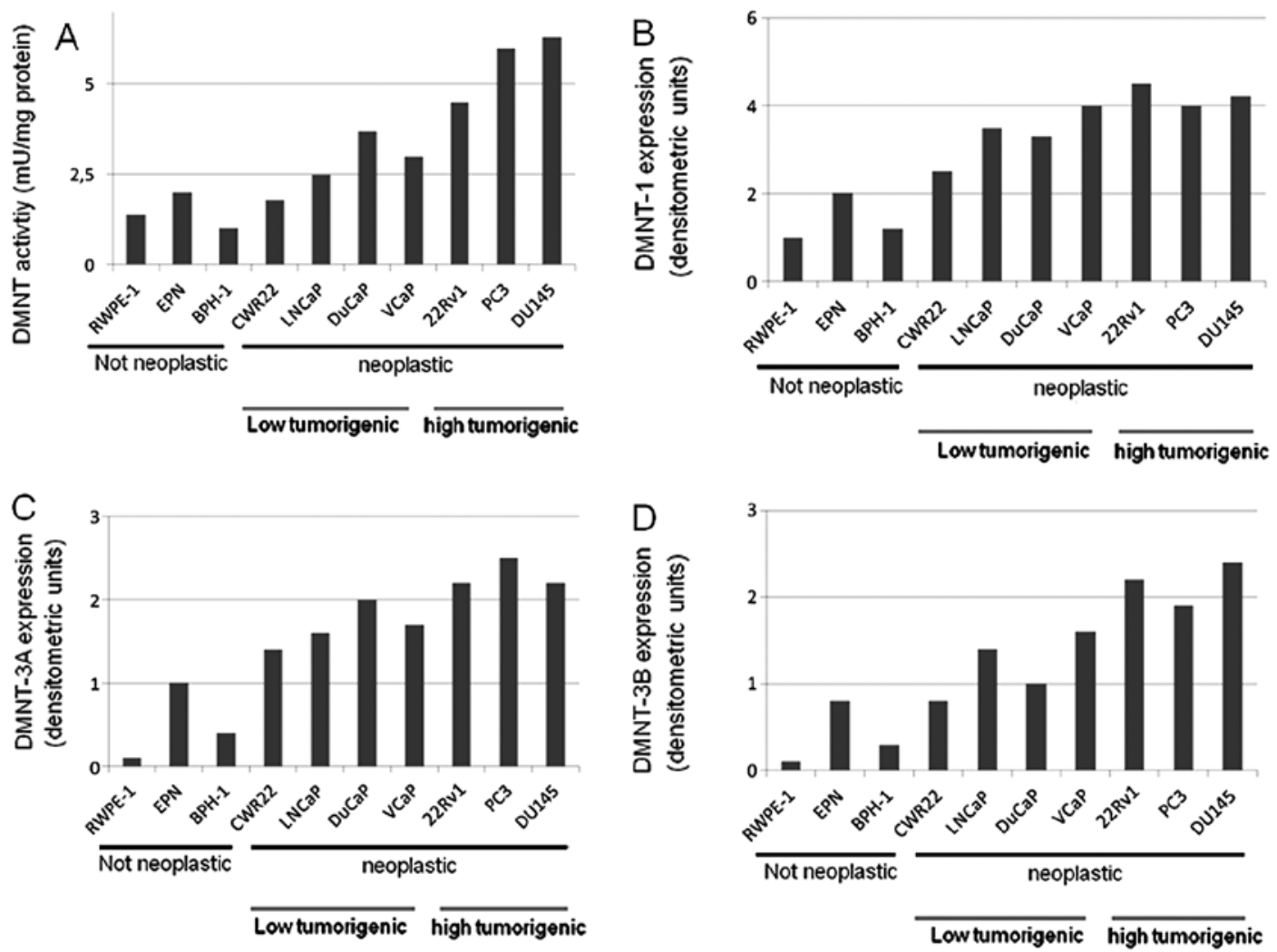

Figure 4. Higher DNMT activity and expression were observed in more aggressive PCa cell lines. (A) DNMT activity as well as the expression of DNMT1 (B), DNMT3a (C) and DNMT3b (D) were higher in neoplastic vs. non-neoplastic prostate epithelial cell lines. Conversely, only DNMT1 expression levels were higher in aggressive/androgen-independent (PC3, DU145 and 22Rv1) compared to low tumorigenic/androgen-dependent (CWR22, LAPC4, LNCaP, DuCaP and $\mathrm{VCaP}$ ) prostate cancer cells. The levels of DNMT3a and DNMT3b were higher in more tumorigenic cells compared to low tumorigenic cells but the differences were not significant.

the levels of DNMT3a also shows that PCa-derived cultures resulted in higher levels of protein compared to BPH cultures. In Fig. 3C we show single values of DNMT1 protein expression in representative BPH (10/10), PCa Gleason $<7(10 / 25)$ and $\mathrm{PCa}$ Gleason $\geq 7(10 / 15)$. The differences between the values of arbitrary densitometric units for DNMT3a protein observed in BPH-derived cultures $(0.25 \pm 0.14 \mathrm{ADU})$ were significantly lower compared with those observed in PCa-derived cultures $(0.83 \pm 0.30$ ADU, $\mathrm{P}<0.001)$. The DNMT3a protein levels were similar in cultures derived from Gleason score $\geq 7$ $(0.82 \pm 0.25 \mathrm{ADU})$ compared to those observed in Gleason score $<7$-derived cultures $(0.84 \pm 0.36$ ADU, NS). Evaluation of the levels of DNMT3b also show that PCa-derived cultures produced higher levels of protein compared to BPH cultures. In Fig. 3D we show single values of DNMT3b protein expression in representative $\mathrm{BPH}(10 / 10), \mathrm{PCa}$ Gleason $<7(10 / 25)$ and $\mathrm{PCa}$ Gleason $\geq 7(10 / 15)$. The differences between the values of arbitrary densitometric units for DNMT3b protein observed in BPH-derived cultures $(0.06 \pm 0.02 \mathrm{ADU})$ were significantly lower compared with those observed in PCa-derived cultures (0.43 \pm 0.17 ADU, $\mathrm{P}<0.001)$. The DNMT3a protein levels were statistically lower in cultures derived from Gleason score $\geq 7$ $(0.34 \pm 0.14 \mathrm{ADU})$ compared to those observed in Gleason score $<7$-derived cultures $(0.52 \pm 0.16 \mathrm{ADU}, \mathrm{NS})$.

Higher DNMT activity and expression are observed in more aggressive PCa cell lines. Next, we analyzed DNMT activity and DNMT expression in different prostate cancer cell lines with different tumorigenic and metastatic capacities. We demonstrated that DNMT activity (Fig. 4A), as well as the expression of DNMT1 (Fig. 4B), DNMT3a (Fig. 4C) and DNMT3b (Fig. 4D) were higher in neoplastic vs. nonneoplastic prostate epithelial cell lines and this was in agreement with previous findings (41). Conversely, only DNMT1 expression was higher in aggressive/androgenindependent (PC3, DU145 and 22Rv1 cell lines) compared to low tumorigenic/androgen-dependent (CWR22, LAPC4, $\mathrm{LNCaP}, \mathrm{DuCaP}$ and $\mathrm{VCaP}$ ) prostate cancer cells. The levels of DNMT3a and DNMT3b were higher in more tumorigenic cells compared to low tumorigenic cells but the differences were not significant. The comparison in PC 3 and $\mathrm{LNCaP}$ cell derivatives possessing higher metastatic potential shows that DNMT1, DNMT3A and DNMT3b were significantly higher (Fig. 5A) in more metastatic PC3-LN4 and LNCaP-Ln5 cell derivatives compared to parental cells.

GSTP1 may be re-expressed or up-modulated by azacitidine. GSTP1 was expressed at high levels only in RWPE-1 and BPH1 cells, EPN cells expressed low levels of this protein whereas all prostatic cancer cell lines analyzed were negative. However, azacitidine was able to increase GSTP1 expression in EPN cells and to restore protein expression in PCa cell lines. In Fig. 5B we show the effects of aza-CR on 3 representative cell lines (EPN, LAPC-4 and PC3). 
A
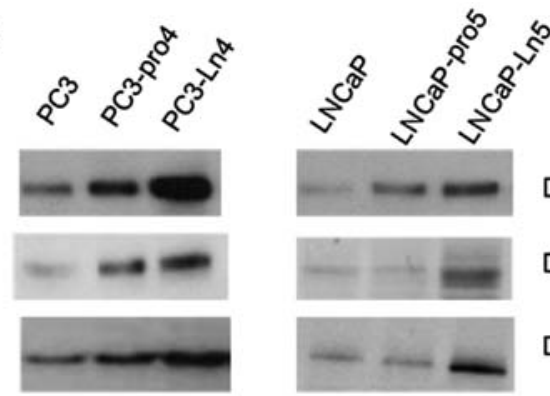

DNMT1

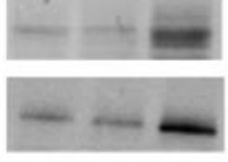

DNMT3a

DNMT3b
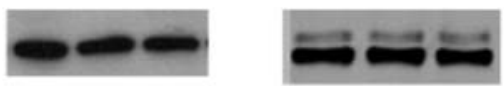

$\beta$-actin

B

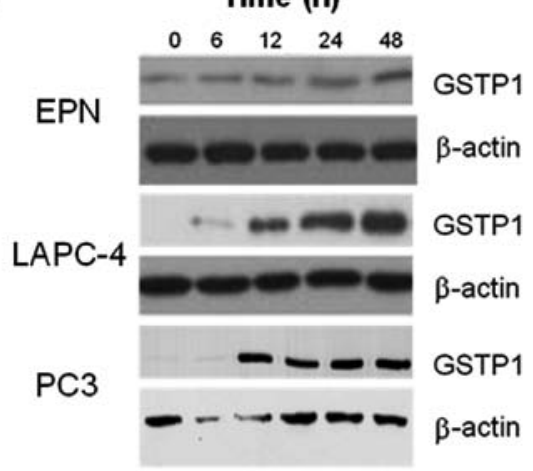

Figure 5. (A) Comparison of DNMT1, DNMT3A and DNMT3b expression levels in PC3 and $\mathrm{LNCaP}$ cell derivatives possessing higher metastatic potential compared to parental cells. (B) GSTP1 may be re-expressed or up-modulated by azacitidine in 3 representative cell lines (EPN, LAPC-4 and $\mathrm{PC} 3$ ).

\section{Discussion}

In recent years, several inhibitors of DNMTs have been developed and evaluated in pre-clinical models and in clinical trials. Among these, 5-azacytidine (5-aza-CR, Vidaza) and 5-azadeoxycytidine (5-aza-dC, decitabine) have received Food and Drug Administration (FDA) approval for the treatment of myelodysplastic syndromes (MDS) (37,38), and these agents and others are being tried alone and in combination with other drugs as cancer therapeutic agents. One major disadvantage of Vidaza or decitabine is that they are nucleoside analogs, whose mechanism of action involves incorporation of the aza-modified base into DNA during DNA synthesis with subsequent covalent trapping of the DNMTs. As with other nucleoside analogs, these drugs can have significant cytotoxicity and can lead to major adverse effects when administered to patients. While these compounds are effective in the treatment of hematologic conditions, clinical trials in solid tumors and in prostate cancer have shown limited or no efficacy $(22,25)$. This may be attributed to inappropriate dose regimens leading to the above-mentioned toxicity-related adverse events. However, as with several anti-target compounds one of the possible obstacles encountered with Vidaza or decitabine, could be the inability to select patients to be enrolled in the clinical studies as well as the inability to monitor the efficacy of the drug if not the conclusion of the study. Based on our findings from the study as well as from a previous report (39), we propose monitoring the expression of DNMT1, DNMT3a and DNMT3b in prostate tissues obtained from biopsy of radical prostatectomy, and evaluating the levels of GSTP before and during the treatment, taking into consideration that GSTP1 (a molecular hallmark of human prostate cancer, the expression of which epigenetic silencing reduces during prostate carcinogenesis and progression) may be re-expressed after 5-aza-CR treatment and is easily measured in a patient's serum and urine (40-42) or circulating tumor cells. In this study, we demonstrated that DNMT activity and the levels of DNMT1, DNMT3a and DNMT3b were significantly higher in primary cultures derived from PCa compared to BPH. Greater differences in the protein levels were, however, observed for DNMT3a and DNMT3b. Next, we demonstrated that DNMT activity and DNMT1 enzyme expression were not statistically higher in cultures derived from Gleason score $\geq 7$ compared to those observed in cultures derived from lower Gleason scores, whereas the levels of DNMT3a and DNMT3b were statistically higher in Gleason scores $>7$. This is in agreement with findings previously observed in human PCa tissue in which we demonstrated that DNMT expression, particularly for DNMT3a and DNMT3b levels, varied with tumor differentiation (34). We then demonstrated that DNMT activity was higher in aggressive androgen-independent compared to low tumorigenic androgen-dependent prostate cancer cells and this was in agreement with previous results (43). In addition, we demonstrated that GSTP1 may be a target for azacitidine treatment since exposure of human prostate cancer cells to $1 \mathrm{mM}$ aza-CR for 1-7 days caused a concentration- and timedependent re-expression of GSTP1, which was correlated with DNMT inhibition. Taken together, our results support that GSTP1 may be considered a useful marker of DNMTi treatment efficacy which will facilitate its use as a biomarker in future clinical trials. The ability to track efficacy of the drug using tissue biopsies or circulating tumor cells at earlier timepoints could greatly assist future clinical trials. In addition, GSTP1 has the potential to improve the assessment of drug efficacy, thus reducing both the duration and cost of a clinical trial, and, secondly, it may improve the welfare of patients in clinical trials by minimizing unnecessary exposure.

\section{References}

1. Jemal A, Siegel R, Ward E, et al: Cancer statistics. CA Cancer J Clin 56: 106-130, 2006.

2. Kirby R: Management of clinically localized prostate cancer by radical prostatectomy followed by watchful waiting. Nat Clin Pract Urol 2: 298-303, 2005.

3. Bedford M and van Helden PD: Hypomethylation of DNA in pathological conditions of the human prostate. Cancer Res 47: 5274-5276, 1987.

4. Nakayama M, Bennett CJ, Hicks JL, Epstein JI, Platz EA, Nelson WG and De Marzo AM: Hypermethylation of the human glutathione S-transferase- $\pi$ gene (GSTP1) CpG island is present in a subset of proliferative inflammatory atrophy lesions but not in normal or hyperplastic epithelium of the prostate: a detailed study using laser-capture microdissection. Am J Pathol 163: 923-933, 2003.

5. Brooks JD, Weinstein M, Lin X, Sun Y, Pin SS, Bova GS, Epstein JI, Isaacs WB and Nelson WG: CG island methylation changes near the GSTP1 gene in prostatic intraepithelial neoplasia. Cancer Epidemiol Biomarkers Prev 7: 531-536, 1998.

6. Nelson CP, Kidd LC, Sauvageot J, Isaacs WB, De Marzo AM, Groopman JD, Nelson WG and Kensler TW: Protection against 2-hydroxyamino-1-methyl-6-phenylimidazo[4,5-b]pyridine cytotoxicity and DNA adduct formation in human prostate by glutathione S-transferase P1. Cancer Res 61: 103-109, 2001. 
7. Lin X, Tascilar M, Lee WH, Vles WJ, Lee BH, Veeraswamy $\mathrm{R}$, Asgari K, Freije D, et al: GSTP1 CpG island hypermethylation is responsible for the absence of GSTP1 expression in human prostate cancer cells. Am J Pathol 159: 1815-1826, 2001.

8. Henderson CJ, Smith AG, Ure J, Brown K, Bacon EJ and Wolf CR: Increased skin tumorigenesis in mice lacking $\pi$-class glutathione S-transferases. Proc Natl Acad Sci USA 95: 5275-5280, 1998.

9. De Marzo AM, Marchi VL, Epstein JI and Nelson WG: Proliferative inflammatory atrophy of the prostate: implications for prostatic carcinogenesis. Am J Pathol 155: 1985-1992, 1999.

10. Kano M, Bell DW, Haber DA and Li E: DNA methyltransferases Dnmt3a and Dnmt3b are essential for de novo methylation and mammalian development. Cell 99: 247-257, 1999.

11. Lu R, Wang X, Chen ZF, Sun DF, Tian XQ, et al: Inhibition of the extracellular signal-regulated kinase/mitogen-activated protein kinase pathway decreases DNA methylation in colon cancer cells. J Biol Chem 282: 12249-12259, 2007.

12. Bai T, Tanaka T, Yukawa K and Umesaki N: A novel mechanism for acquired cisplatin-resistance: Suppressed translation of death-associated protein kinase mRNA is insensitive to 5-aza2 -deoxycitidine and trichostatin in cisplatin-resistant cervical squamous cancer cells. Int J Oncol 28: 497-508, 2006.

13. Gravina GL, Festuccia C, Marampon F, Popov VM, Pestell RG Zani BM and Tombolini V: Biological Rationale for the use of DNA methyltransferase inhibitors as new strategy for modulation of tumor response to chemotherapy and radiation. Mol Cancer 9: 305-321, 2011

14. Zorn CS, Wojno KJ, McCabe MT, Kuefer R, Gschwend JE, et al: 5-aza-2'-deoxycytidine delays androgen-independent disease and improves survival in the transgenic adenocarcinoma of the mouse prostate mouse model of prostate cancer. Clin Cancer Res 13: 2136-2143, 2007

15. Morey Kinney SR, Smiraglia DJ, James SR, Moser MT, Foster BA and Karpf AR: Stage-specific alterations of DNA methyltransferase expression, DNA hypermethylation, and DNA hypomethylation during prostate cancer progression in the transgenic adenocarcinoma of mouse prostate model. Mol Cancer Res 6: 1365-1374, 2008

16. Stewart DJ, Issa JP, Kurzrock R, Nunez MI, Jelinek J, et al Decitabine effect on tumor global DNA methylation and other parameters in a phase I trial in refractory solid tumors and lymphomas. Clin Cancer Res 15: 3881-3888, 2009.

17. Iwata H, Sato H, Suzuki R, Yamada R, Ichinomiya S, Yanagihara M, et al: A demethylating agent enhances chemosensitivity to vinblastine in a xenograft model of renal cell carcinoma. Int J Oncol 38: 1653-1661, 2011.

18. Perry AS, Foley R, Woodson K and Lawler M: The emerging roles of DNA methylation in the clinical management of prostate cancer. Endocr Relat Cancer 13: 357-377, 2006

19. Pulukuri SM and Rao JS: Activation of p53/p21Waf1/Cip1 pathway by 5-aza-2'-deoxycytidine inhibits cell proliferation, induces pro-apoptotic genes and mitogen-activated protein kinases in human prostate cancer cells. Int J Oncol 26: 863-871, 2005.

20. Festuccia C, Gravina GL, D'Alessandro AM, Millimaggi D, Di Rocco C, Dolo V, et al: Downmodulation of dimethyl transferase activity enhances tumor necrosis factor-related apoptosis-inducing ligand-induced apoptosis in prostate cancer cells. Int J Oncol 33: 381-388, 2008

21. Festuccia C, Gravina GL, D'Alessandro AM, Muzi P, Millimaggi D, Dolo V, et al: Azacitidine improves antitumor effects of docetaxel and cisplatin in aggressive prostate cancer models. Endocr Relat Cancer 16: 401-413, 2009.

22. van Groeningen CJ, Leyva A, O'Brien AM, Gall HE and Pinedo HM: Phase I and pharmacokinetic study of 5-aza2'-deoxycytidine (NSC 127716) in cancer patients. Cancer Res 46: 4831-4836, 1986.

23. Thibault A, Figg WD, Bergan RC, Lush RM, Myers CE, et al: A phase II study of 5-aza-2'deoxycytidine (decitabine) in hormone independent metastatic (D2) prostate cancer. Tumori 84: 87-89, 1998.

24. Kastl L, Brown I and Schofield AC: Altered DNA methylation is associated with docetaxel resistance in human breast cancer cells. Int J Oncol 36: 1235-1241, 2010

25. Gravina GL, Marampon F, Piccolella M, Motta M, Ventura L, Pomante R, Popov VM, Zani BM, Pestell RG, Tombolini V, Jannini EA and Festuccia C: Hormonal therapy promotes hormone-resistant phenotype by increasing DNMT activity and expression in prostate cancer models. Endocrinology 152: $4550-4561,2011$.
26. Gravina GL, Festuccia C, Millimaggi D, Dolo V, Tombolini V, de Vito $M$, Vicentini $C$ and Bologna $M$ : Chronic azacitidine treatment results in differentiating effects, sensitizes against bicalutamide in androgen-independent prostate cancer cells. Prostate 68: 793-801, 2008

27. Gravina GL, Marampon F, Di Staso M, Bonfili P, Vitturini A, Jannini EA, Pestell RG, Tombolini V and Festuccia C: 5-Azacitidine restores and amplifies the bicalutamide response on preclinical models of androgen receptor expressing or deficient prostate tumors. Prostate 70: 1166-1178, 2010.

28. Sinisi AA, Chieffi P, Pasquali D, Kisslinger A, Staibano S, Bellastella A and Tramontano D: EPN: a novel epithelial cell line derived from human prostate tissue. In Vitro Cell Dev Biol Anim 23: $165-172,2002$

29. Tepper CG, Boucher DL, Ryan PE, et al: Characterization of a novel androgen receptor mutation in a relapsed CWR22 prostate cancer xenograft and cell line. Cancer Res 62: 6606-6612, 2002.

30. Craft N, Shostak Y, Carey M, et al: A mechanism for hormoneindependent prostate cancer through modulation of androgen receptor signaling by the HER-2/neu tyrosine kinase. Nat Med 5: 280-288, 1999.

31. Korenchuk S, Lehr JE, MClean L, Lee YG, Whitney S, Vessella R, Lin DL and Pienta KJ: VCaP, a cell-based model system of human prostate cancer. In Vivo 15: 163-168, 2001

32. Lin DL, Tarnowski CP, Zhang J, Dai J, Rohn E, Patel AH, Morris MD and Keller ET: Bone metastatic LNCaP-derivative C4-2B prostate cancer cell line mineralizes in vitro. Prostate 47: 212-218, 2001.

33. Pettaway CA, Pathak S, Greene G, Ramirez E, Wilson MR, Killion JJ and Fidler IJ: Selection of highly metastatic variants of different human prostatic carcinomas using orthotopic implantation in nude mice. Clin Cancer Res 2: 1627-1636, 1996.

34. Festuccia C, Vincentini C, di Pasquale AB, Aceto G, Zazzeroni F, Miano L and Bologna M: Plasminogen activator activities in short-term tissue cultures of benign prostatic hyperplasia and prostatic carcinoma. Oncol Res 7: 131-138, 1995.

35. Festuccia C, Angelucci A, Gravina GL, Muzi P, Miano R, Vicentini $\mathrm{C}$ and Bologna $\mathrm{M}$ : Epithelial and prostatic marker expression in short-term primary cultures of human prostate tissue samples. Int J Oncol 26: 1353-1362, 2005.

36. Gravina GL, Biordi L, Martella F, Flati V, Ricevuto E, Ficorella C, Tombolini V and Festuccia C: Epigenetic modulation of PTEN expression during antiandrogenic therapies in human prostate cancer. Int J Oncol 35: 1133-1139, 2009.

37. Kaminskas E, Farrell A, Abraham S, Baird A, Hsieh LS, Lee SL, Leighton JK, et al: Approval summary: azacitidine for treatment of myelodysplastic syndrome subtypes. Clin Cancer Res 11: 3604-3608, 2005.

38. Kantarjian H, Issa JP, Rosenfeld CS, Bennett JM, Albitar M, DiPersio J, Klimek V, et al: Decitabine improves patient outcomes in myelodysplastic syndromes: results of a phase III randomized study. Cancer 106: 1794-1803, 2006.

39. Chiam K, Centenera MM, Butler LM, Tilley WD and BiancoMiotto T: GSTP1 DNA methylation and expression status is indicative of 5-aza-2'-deoxycytidine efficacy in human prostate cancer cells. PLoS One 6: e25634, 2011.

40. Mulder TP, Peters WH, Wobbes T, Witteman BJ and Jansen JB: Measurement of glutathione S-transferase P1-1 in plasma: pitfalls and significance of screening and follow-up of patients with gastrointestinal carcinoma. Cancer 80: 873-880, 1997.

41. Oude Ophuis MB, Mulder TP, Peters WH and Manni JJ: Plasma glutathione S-transferase P1-1 levels in patients with head and neck squamous cell carcinoma. Cancer 82: 2434-2438, 1998.

42. Prior C, Guillen-Grima F, Robles JE, Rosell D, FernandezMontero JM, Agirre X, et al: Use of a combination of biomarkers in serum and urine to improve detection of prostate cancer. World J Urol 28: 681-686, 2010.

43. Patra SK, Patra A, Zhao H and Dahiya R: DNA methyltransferase and demethylase in human prostate cancer. Mol Carcinog 33: 163-171, 2002. 